\title{
Conscious Entertainment: Commitment in the Reggae Lyrics of Clinton Fearon and Protoje
}

\section{David Bousquet}

\section{(2) OpenEdition \\ 1 Journals}

Electronic version

URL: https://journals.openedition.org/ces/4964

DOI: $10.4000 /$ ces.4964

ISSN: 2534-6695

Publisher

SEPC (Société d'études des pays du Commonwealth)

\section{Printed version}

Date of publication: 1 September 2015

Number of pages: $67-78$

ISSN: 2270-0633

\section{Electronic reference}

David Bousquet, "Conscious Entertainment: Commitment in the Reggae Lyrics of Clinton Fearon and Protoje", Commonwealth Essays and Studies [Online], 38.1 | 2015, Online since 10 April 2021, connection on 10 July 2021. URL: http://journals.openedition.org/ces/4964 ; DOI: https://doi.org/10.4000/ces. 4964

\section{(c) (i) $\odot$}

Commonwealth Essays and Studies is licensed under a Licence Creative Commons Attribution - Pas d'Utilisation Commerciale - Pas de Modification 4.0 International. 


\section{Conscious Entertainment: Commitment in the Reggae Lyrics of Clinton Fearon and Protoje}

This article provides an analysis of the lyrics of Clinton Fearon and Protoje, two major figures of contemporary Jamaican popular music. They are consistently described as committed singers/songwriters and proficient lyricists in a context where reggae music and culture are seen as falling into the excesses of violence and "slackness." A study of commitment in their respective last two albums will show that despite some contradictions, conscious reggae is still alive today.

This article provides an analysis of the lyrics and persona construction of two major figures of contemporary Jamaican popular music that are consistently described as committed singers/songwriters and proficient lyricists in a context where reggae music and culture are seen as falling into the excesses of violence and "slackness."1 Clinton Fearon (born 1951) has been involved in all major developments of reggae music since the 1960 s as a former member of The Gladiators, one of the best-known vocal trios of the roots reggae era. He is also an accomplished bass player, singer and composer and has worked as a session musician for major reggae producers like Sir Coxsone Dodd, Lee Scratch Perry, Joe Higgs and Yabby You. He has been living and working in Seattle since 1987 and has recorded some of the most notable roots reggae albums of the last two decades with the Boogie Brown Band. His last two releases will be my subject matter here, Mi Deh Yah (2012) and Goodness (2014). Protoje (born 1981) is an upcoming reggae artist based in Kingston, Jamaica. He is regularly quoted as the figurehead of a new generation of roots singers, DJs and bands who revive the type of conscious reggae that had gradually disappeared from the charts since the 1990s. Unlike Fearon, Protoje is primarily a reggae DJ, performing spoken word poetry to the pre-recorded instrumental tracks or "riddims" composed and produced by major figures of the Jamaican music industry like Don Corleon and Phillip Winta James. My reading of his work will be focused on his last two records: The 8-Year Affair (2013) and Ancient Future (2015)..$^{2}$

Despite their many differences - in age, style, themes, and persona construction both artists are regularly portrayed as figures of commitment in reggae music and share in a "reggae revival" approach many critics and fans have called for in the last decades. ${ }^{3}$ Their commitment, most evident in their lyrics, is seen as an indication of the quality of

1. The term "slackness" is used in reggae culture to refer to songs with sexually explicit lyrics and whose main topic is the graphic description of sexual acts. It is generally opposed to "conscious" reggae which predominantly deals with social commentary and cultural and political struggles. The dominant narrative on reggae music history is that of a gradual rise to fame and recognition through the 1960 s and 1970 s followed by a long downfall into computerisation, sex and violence from the mid-1980s onwards. Versions of this narrative can be found in Barrow \& Dalton, Bradley and Stolzoff among others.

2. Further bibliographical information on the corpus can be found at the end of this article. Further biographical information on Clinton Fearon and Protoje can be found respectively at $<$ http://www.clintonfearon.com/ $>$ and $<$ http:// www.protoje.com/ $>$. All the lyrics quoted in this article are taken from the booklets of the four records, which do not include any punctuation.

3. The reggae revival movement is generally said to have started around 2010 with the emergence of a new generation of musicians who revived the themes and music of 1970s reggae. Protoje is often quoted as the figurehead of the movement and has a song entitled "Reggae Revival" on the album The 8-Year Affair. Other names associated with the 
their work and a proof of their high moral standards which oppose, sometimes explicitly, the slackness of hard-core dancehall music. Both artists perpetuate the image and role - social and artistic - of the righteous Rastaman that became the icon of reggae during its heyday in the 1970s. But this commitment is also a tool in the marketing of these artists in the international pop music industry: they both appeal to US and European audiences who favour conscious reggae over the rougher sounds of the Kingston dancehall scene, and they both have close ties to the French reggae movement which has been instrumental in the revival of roots reggae music in the last two decades. ${ }^{4}$ Such a marketing strategy creates frictions in Jamaica, where this type of reggae appeals to a minority of listeners, but also in Europe where the message of the righteous Rastaman can sometimes be heard as a form of moral or religious conservatism, especially when it comes to gender issues.

This article will look in more detail at how Clinton Fearon and Protoje negotiate the complexities of constructing the image of a committed artist. Since both of them refer more or less explicitly to Rastafarianism, I will first study how the notion of commitment can be approached through the complex combination of moral and political values that Rastafarians call "livity." I will then analyse the specific role played by music in this definition of commitment and the vision of the artist's role in his/her community it entails. To conclude, I will mention some of the differences between Fearon's and Protoje's visions of commitment and some of the problems linked to being a committed artist in the contemporary pop music industry.

The critical decision to study reggae lyrics as valuable literary material is inspired by the work of academics like Paul Gilroy, Carolyn Cooper or Kwame Dawes, who have all shown that reggae lyrics are part of an oral/scribal continuum in the Caribbean which goes from the traditional, uptown approach of poets like Derek Walcott to the ghetto sounds of dancehall DJ lyrics, including the more hybrid forms of dub poetry or reggae lyrics. Further references to this theoretical framework will be made in the course of this article, especially in the discussion of the antiphonic, dialogical dimension of Fearon's and Protoje's lyrics, which is a mark of their commitment to the tradition of Afro-Caribbean discourse and New World African music.

\section{Rasta Livity}

Commitment in the work of Fearon and Protoje can be first approached through the notion of "livity," an expression used by practitioners of the Rastafari cult to refer to their specific way of life. ${ }^{5}$ More precisely, this term refers to the articulation of personal behaviour to a set of philosophical, political and moral values, in other words to an ethos. In their construction of themselves as righteous Rastamen, Fearon and Protoje extensively borrow from a vast repertoire of oral and written texts, imagery and prac-

movements are the singers and DJs Chronixx, Jesse Royal, Kabaka Pyramid, Jah9 and the bands Rootz Underground, Pentateuch, Raging Fyah and Uprising Roots.

4. There has been an important reggae scene in France since the mid-1980s. More recently, French reggae musicians and producers have played an increasing role in the international development of the music. Significantly, both Fearon and Protoje work with French labels: Makasound/Makafresh, Chapter Two and Baco Records.

5. The word "livity" is one of the many linguistic creations typical of Rastafarianism and generally referred to as dread or Rasta talk. It is not included in dictionaries of Jamaican Patwah but unofficial Internet sources provide definitions such as "a lifestyle, a way of living" (www.urbandictionary.com) or "harmony in a natural world and living faith" (www.yourdictionary.com). For more information on dread talk see Pollard. 
tices that has been developed in the Rastafari movement since the 1930s and has had an important impact on reggae music and culture. ${ }^{6}$

The Rastafarian livity that is promoted by Fearon and Protoje relies on a profound moral commitment to the figure of Jah Rastafari which engages the Rastaman in the struggle for good and against evil. Through the ritual practice of meditation, which includes, notably, the regular reading and interpreting of the Bible, the Rastaman achieves a vision of an inner, hidden truth that is revealed to him and acts as a moral foundation for his individual and collective behaviour. Such a vision is clearly expressed by Protoje in "Who Knows":

When me see Jah me see a way

Drastically stray from hypocrisy I say

Every man to them owna philosophy

A live the proper way, and then me read a chapter daily

The song "Hail Rastafari" displays the same typical pattern, in which Jah is seen as a shepherd guiding his flock safely "on the straight road" even in the hardest of times. Although he does not refer explicitly to Ras Tafari, Fearon resorts to very similar imagery in the song "Jamdown Boogie" to anchor his commitment in the revelation of a moral definition of "goodness":

I man got a plan an' mi nah go wait too long

To work for the good I know

I man got a plan an' mi ha fi stand up strong

To fight for the good I know

The notion of living the right way or of fighting for good is at the core of the Rastafarian way of life but should not be seen as a strict and unchanging moral code; revelation is primarily a process of discovery that is never completely achieved. Fearon for example does not claim to fight for a universal, abstract notion of moral righteousness but only "for the good I know," thus limiting the definition of goodness to what has been revealed to him. Similarly, Protoje claims "every man to them owna philosophy," thereby refusing to produce too narrow a definition of the "proper way" of life. It should be noted here that the Rastafari cult cannot be compared to a religion, despite the influence of Christianity - and to a lesser extent of Judaism and Islam - on the doctrine. As critics like Michael Barnett have noted, Rastafarianism is a highly individualised and decentralised cult in which each member has a great freedom to think and act as s/ he pleases.

Equally, Rastafarianism should not be seen solely as a moral, spiritual or religious doctrine. It entails a political struggle for survival and self-sufficiency which draws on the African heritage of community life and on modern Western ideologies like socialism and communism. ${ }^{7}$ In other words, the revelation of an inner truth and the commitment to strong moral principles is equally a fight for liberation and emancipation, both on

6. Ras Tafari or more commonly Jah Rastafari are some of the names given to Ethiopian emperor Haile Selassie I who is recognised as the central figure of the Rasta cult. For more information on Selassie himself and on Rastafarianism, see Barrett, Campbell, Chevannes, Owens and Zips.

7. Hélène Lee for instance provides useful insight into the development of Rastafarianism through contacts with other ideological frameworks by tracing the history of Leonard Howell in her book The First Rasta. She shows that Howell had been in contact with many socialists, communists and anarchists during his three trips around the world on board commercial ships in the years 1916 to 1919. Horace Campbell provides useful information on the political dimension of Rastafarianism as a culture of resistance in Rasta and Resistance. 
an individual and collective level. The Rastafari philosophy is just as much a loose yet coherent set of moral principles as a form of political resistance and working-class ethos based on the empowerment of the dispossessed slaves, in which music plays a central role. One of the main goals of the Rastafari doctrine is to help to rebuild the lost power and glory of African slaves and thus reverse the hierarchies of slavery and (post) colonial society. As Protoje clearly states in "Protection," spiritual and political concerns are deeply intertwined: "This was built on the power of the truth / Discovering the cowards and empowering the youth."

Rastafarian livity is primarily conceived as the defence and promotion of a natural and simple way of life - which Rastas call "naturality" - a form of ecological commitment to respect one's environment and to use only the natural resources necessary for one's survival. This natural way of life is intimately linked to the notion of self-sufficiency developed notably by Jamaican Maroons. ${ }^{8}$ This in turn implies a fierce condemnation of consumerism and capitalism which are seen as ways of producing and consuming opposed to Rastafarian values. In "Hail Rastafari," Protoje expresses his view of naturality and its moral and political dimensions:

I said He giveth and He taketh away

Understanding nothing is belonging to me

Earth will provide you with the necessity

Me say simplicity is what we use in these days

This way of life is threatened by the development of capitalism and, in that respect, Rastafarianism recycles the old Christian tradition of denouncing vanity and the accumulation of material wealth. In "What A World," Fearon exposes the consequences of the capitalist appropriation of common goods:

Food water and clean air

So much has been taken away

Cats and dogs the birds and the bees have lost their wild

So much has been taken away

He produces a similar reflection in "Freedom":

The Sun the Moon the stars they're all for free

No matter how much Wall Street charge us

Earth space wind and fire they're all for free so

Don't sell your soul to the mighty dollar

$[\ldots]$

Take the tag from off yourself there's no price

The spiritual and political struggle of working-class Africans for freedom, equal rights and justice is expressed through the "us and them" rhetoric that is a typical feature of the Rastafarian philosophy and of many reggae songs. Again, the moral and political registers are combined to denounce oppression and exploitation, as in Protoje's "Who Can You Call": "In spite of all these notes I see the pattern them developing / Morality secondary to money greed and jealousy." An almost similar pattern can be found in Fearon's "Better Days":

8. Maroons are escaped slaves and their descendants who built self-sufficient, autonomous communities away from the plantations and resisted physically and culturally the colonial order of slave owners. In Jamaica, this tradition of resistance had a profound impact on the emergent Rastafari movement as Leonard Barrett and Horace Campbell, among others, have shown. 
How much more must they take us

How much more must they break us

With their false pretence all they want is

More money more money

How much more must they use us

How much more must they abuse us

With their false pretence all they want is

More power more power

The righteous Rastaman must then not only denounce the abuses and excesses of modern society, but put into practice his values by living a life that is an act of resistance against the "shitstem." Against the vision promoted by the social and racial ruling elites, the Rasta singer or DJ must commit to the fight for spiritual redemption and political emancipation, like Fearon in "Better Days":

I'm gonna live my life to the fullest

I'm gonna do my best cause

Better days are coming this I know

\section{Music, Commitment and Community}

As evoked repeatedly in the above discussion of the notion of livity, the commitment of Rasta reggae artists like Fearon and Protoje cannot be understood at the individual level only as the adherence to a moral code of conduct revealed by a higher spiritual authority. Commitment is always equally linked to a community and engages the role of the artist within this community. In that respect, music appears as a powerful medium to create and maintain social relationships between the singer or DJ and his/her listeners. Indeed, music is a central pillar of the Rastafarian livity: it represents the superiority of spiritual and artistic concerns over material and economic needs and is an instrument of liberation. As Paul Gilroy has shown, music was the only autonomous sphere for the political and cultural expression of the slaves in the plantation economy. For that reason, it concentrates a number of social and discursive functions that are generally found in other art forms and social practices in different cultures. ${ }^{10}$ This phenomenon can be observed particularly well in the lyrics of reggae songs - and more generally of many musical genres of the black Atlantic - which contain elements of theology, sociology, philosophy and other types of discourse expressed in a powerful poetic language.

To Rastafarians, music has a magical, cathartic power to relieve mankind from the hardships of life, a notion which is expressed in the proverb "word sound have power." 11 Since it is always coupled with dance in reggae culture, music enables a liberation of the body and the soul, and it is a means of physical release, spiritual elevation

9. Another typical example of dread talk, this word exemplifies the Rastafarian habit of replacing certain morphemes in English words by others that denote more clearly their "true" meaning. Hence "oppression" (up-pression) becomes "downpression," "Kingston" "Killsome" and "system" "shitstem." For more information on this point, see Pollard.

10. "The power and significance of music within the black Atlantic have grown in inverse proportion to the limited expressive power of language. It is important to remember that the slaves' access to literacy was often denied on pain of death and only a few cultural opportunities were offered as a surrogate for the other forms of individual autonomy denied by life on the plantations [...]. Music becomes vital at a point at which linguistic and semantic indeterminacy/ polyphony arise amidst the protracted battle between masters, mistresses, and slaves" (Gilroy, The Black Atlantic 74).

11. This expression is typical of Rasta talk and is used to refer to the specific use of language and music in collective rituals of celebration and healing (see Pollard). For a discussion of the cathartic power of reggae dances, see Gaye. 
and political empowerment. This is what makes music an integral part of the Rastafarian livity: playing music is not only an occupation and a source of income, or a form of entertainment, it is in itself a form of livity that artists must follow scrupulously. Rasta artists are thus committed to music itself, and vow to practise it with utmost dedication. It is the case of Fearon in "Rock And A Hard Place" where the persona of the poet and musician, "comin' from the country with [his] little guitar," declares:

I give and I give I give my sweat my tears and

I want to know why such a rock and a hard place

I give and I give I give my heart my soul and

I want to know why such a rock and a hard place

In these lines as in others from Fearon's songs, playing music is seen as a form of craft that is not essentially different from that of the worker or the peasant: it implies hard physical work despite its spiritual dimension. In "Working For The Man," a song describing the hard working conditions of miners, Fearon declares that he "will always sing / draw lose or win" and by doing so reconnects with the roots of reggae to be found in blues, gospel and even more precisely in slave songs and work songs. In these texts, the cathartic and social function of music is strongly asserted as a form of conscious entertainment which helps working-class audiences to forget about the tough realities of everyday life, but also provides spiritual elevation and political reflection. Music then must not be used to make money but should be maintained in its redemptive dimension as Fearon makes clear in "John Jones":

Oh my brother beware

Don't be your worst enemy

Don't get caught in the hype

And win the fools grammy

By the sweat of your brow

You'll get your daily bread

A similar refusal to divert music from its spiritual and social function by making it a primarily commercial activity can be found in Protoje's "Music From My Heart," which can be read as a paradigm for the role of music in Rastafarian livity. Significantly, Protoje also uses the example of the Grammy Awards to denounce the submission of music to economic imperatives and to express a form of musical resistance to the influence of the North American pop music industry on reggae: ${ }^{12}$

Mommy if I never win a Grammy don't you ever cry for me

No billboard up in the sky for me

If I never get to put a plaque on Don's wall ${ }^{13}$

I'll appreciate the fact that even one sold

12. The Grammy Awards ceremony has often been criticised for putting more emphasis on commercial success than on critical recognition. In the case of reggae, since the introduction of the Grammy Award for Best Reggae Album in 1985, Bob Marley's sons Ziggy, Damian and Stephen have received ten awards in total. If one adds the awards given to former members of The Wailers Peter Tosh and Bunny Wailer and to their former producer Lee Scratch Perry, it appears that more than half the awards ever given to reggae artists participate in the construction of the Marley legend, thereby leaving very little room for more grassroots reggae productions (see Stephens). More generally, the reggae music industry seems to be quite alien to North American business practices, which might explain the contempt of many reggae artists for the Grammy Awards (see Manuel \& Marshall).

13. This is a reference to Don Corleon, producer of The 8-Year Affair. 
Similarly, the chorus of the song establishes a strong link between music and the Rastafarian livity more generally:

I'm just making music from my heart

Not music for the charts no

No I won't get caught up in all of the things dem woulda start

To stray I from I path

Won't fall victim to dem conduct

The importance and centrality of music in Rastafarian thought, its power to heal and redeem, implies that musicians play a specific role in their community. This role has been theorised with conceptual models from the African diaspora like that of the griot in reggae itself and in many other musical genres of the black Atlantic. ${ }^{14}$ The singer or DJ is given authority within his/her community to express musically and in his/her lyrics the concerns of the community. This authority is moral, political and spiritual and the singer/DJ can be seen primarily as a spokesperson for the community. This implies very diverse roles which include elements of the preacher or prophet (giving warning of divine punishment), of the entertainer (mostly as an agent of catharsis), of the military leader, of the father - or more rarely mother - figure, and of the teacher/professor. The commitment of the Rasta singer to the community and his/her spiritual and social role is clearly expressed by Protoje in "Music From My Heart":

Now I see what is my responsibility

The blessings I've received I must do my best to lead then

'Cause when people they stand in front of me with them ears attentively

Well then I do my best to reach them

For if I am making music from my soul and know my role

In other songs, Protoje consistently creates his own persona as that of a warrior ("Who Dem A Program"), a king ("Black Cinderella," "Protection") or a prince ("Who Dem A Program"), and as a general or military leader ("I n I," "Bubblin"). In "The 8-Year Affair," he also explains at some length why this social and spiritual responsibility entrusted to him by his community should not be confused with celebrity - which is just another form of vanity - by engaging in a comparison with the figure of Usain Bolt. In "The Flame," he declares that he would "rather be spiritually attained than critically acclaimed," before once again reasserting the redeeming function of music:

Then it becomes less about the tune them wah a spin

But the knowing that the work was the best it coulda been

Having the team deh pon the road a tour with me

No mean a thing if the message no have the purity

And so me say substance over hype

Similar characterisations of the role of the singer and musician can be found in Fearon's lyrics, notably in "Life Is A Journey" where he builds his persona as that of "a fighter" and "a survivor" having no choice but to tell "the story of [his] life" in the form of a song.

But the lyrics of Protoje and Fearon display a form of social commitment on a deeper level, which is that of the dialogism and antiphony that characterise most black Atlantic musical styles. According to Paul Gilroy, music from the African diaspora is

14. For more information on the social role of musicians and the exploration of theoretical models for black intellectuals, see Cooper (Noises In The Blood), Gilroy (The Black. Atlantic), and Glissant. 
fundamentally structured around the call and response pattern in which an individual voice is answered by a chorus (The Black. Atlantic 78-9). Though most visible in gospel music and services, this phenomenon can also be observed in Rastafarian groundations ${ }^{15}$ and in reggae music. Antiphony can be understood as a reconstruction in the New World of the communal function of music in West African societies and cultures from which most slaves originated. To Edouard Glissant, music, just like many other art forms from Caribbean cultures, is of a fundamentally relational nature: it always already includes a form of address or relationship to others and thereby establishes its social and communal function (382-3).

This social function expresses itself in the performance of music. Even though a lot of reggae music is recorded, the ultimate aim of singers, DJs and musicians remains the live performance since it is the only way in which music can actually create links within a group of people. To Gilroy, there is a "premium which all these black diaspora styles place on the process of performance" (The Black Atlantic 105) which can be analysed thus:

$[T]$ here is a democratic, communitarian moment enshrined in the practice of antiphony which symbolises and anticipates (but does not guarantee) new, non-dominating social relationships. Lines between self and other are blurred and special forms of pleasure are created as a result of the meetings and conversations that are established between one fractured, incomplete, and unfinished racial self and others. Antiphony is the structure that hosts these essential encounters. (79)

In other words, the relationship between the committed artist and the community of his/ her listeners is not just alluded to in song lyrics, it literally takes place in the process of musical performance. It is in this way that the numerous addresses of the singer or DJ to his/her audience must be understood. It would be impossible to discuss all the examples from my corpus in the space of this article, but both Fearon and Protoje regularly resort to such addresses to inscribe in their lyrics the antiphonic relationship between the individual voice of the artist and the chorus of the listeners. The song "The 8-Year Affair," which could be understood from its title as primarily concerned with a romantic relationship, is indeed entirely devoted to a discussion of the relationship between Protoje and his fans since the beginning of his career. This relationship is seen as the very foundation of the artist's work, without which his work would never be complete: "I've always made it clear / That you would be here with me in this Eight Year Affair." The end of the song reinforces the idea that this is the opening of a ritual ceremony which brings together the artist and his/her listeners in something that highly resembles Rastafarian collective meditations:

Six days of voicing no rest until the seventh day

Then drop the Album pon dem hoping say it resonate

$[\ldots]$

I'd like to welcome you to The Eight Year Affair

Yes and I thank you for being here with I\&I you know

Along this journey

Similar forms of address can be detected in many of Fearon's and Protoje's songs notably through a specific use of the "I" and "you" pronouns. In "Life Is A Journey" for

15. Groundations are Rastafarian gatherings where participants sing and play music but also engage in collective readings and discussions of Biblical passages. 
instance, Fearon also states the centrality of his relationship to his audience in his work: "I have got a song the story of my life / I am gonna sing this song and I hope that you will understand." It is worth repeating that such passages cannot be read solely as metaphorical: in the performance of these songs, the address to the audience becomes direct and real, and it calls for an actual response from the community.

Antiphony is expressed in many other ways in the work of Fearon and Protoje, from very concrete forms of address to subtle evocations in the words or the musical arrangements. For example, Protoje's albums feature a number of other artists' voices that make the dialogical nature of his lyrics clearly audible even in recorded form, many songs being duets or even trios. ${ }^{16}$ Both Fearon and Protoje resort to backing vocals to inscribe the choral response to their voice in musical arrangements; often, these responses will be sung along by the audience in live performances. Very often too, the voice of the artist is answered by an instrument, or instruments answer each other, thus placing antiphony at the very heart of musical composition itself.

Both lyricists also resort to quotations and intertextuality to make other voices heard behind their own, and thus again reinforce the unfinished, open and dialogical nature of their lyrics. Protoje for example alludes in many songs to prior reggae singers and DJs like Bob Marley, Peter Tosh, Ini Kamoze or Papa San. This is a way for him to situate his work within a roots reggae tradition, thus emphasising the Rasta livity discussed above by anchoring it in a historical legacy. But significantly, he also makes musical quotations by sampling and reusing in his music melodies or gimmicks from other reggae songs. Though this type of musical quotation is ubiquitous in reggae music, Protoje is one of the only DJs to actually provide proper referencing for all the musical material he uses. In this way he strengthens the idea of a reggae tradition but also expands the principles of antiphony and dialogism by literally making other voices heard together with his own. ${ }^{17}$

In the case of Fearon, intertextuality is rather linked to the constant quoting and reinterpreting of the Bible, which is typical of Rastafarianism, and also to the recurring use of proverbial knowledge that is characteristic of the Jamaican oral tradition. ${ }^{18}$ Again, these are ways to place his lyrics within a larger tradition and to deconstruct implicitly the idea of the poet as the individual author of texts. In that respect, Fearon's lyrics are also fundamentally dialogical and need to be complemented by the audience's input, especially in the performance process. In other words, we can say with Gilroy that the lyrics under consideration here are indeed "radically unfinished" (The Black Atlantic 105) and should rather be seen as a stage in a process of meaning construction which is fundamentally collective. Just like Rasta livity implies a link between individual behaviour and collective values, antiphony implies that lyrics are never only the product of an individual voice but of a constant dialogue between this voice and a communal chorus. ${ }^{19}$

16. On The 8-Year Affair, Protoje has three duets out of fourteen songs: "Someone Like You" with Tessanne Chin, "Reggae Revival" with Romain Virgo, and "Shot By Love" with Toi. On Ancient Future, this number is increased to five (out of eleven): "Protection" featuring Mortimer, "Who Knows" featuring Chronixx, "Love Gone Cold" featuring Sevana, "Sudden Flight" featuring Sevana and Jesse Royal, and "The Flame" featuring Kabaka Pyramid.

17. On Ancient Future, five songs contain either samples or "interpolations" from classic reggae songs by artists like Ini Kamoze, Zap Pow, Prince Buster or Linval Thompson. The precise references for these can be found in the accompanying booklet.

18. For more information on the Biblical intertext in Rastafarianism and reggae, see Breiner. For a discussion of proverbs in Jamaican culture and reggae, see Prahlad.

19. The unfinished character of reggae lyrics as texts can also be observed in the fact that they are open to change and a certain degree of improvisation, especially in the context of live performances. Despite being the products of a 


\section{The Complexities of Commitment}

So far, the discussion of the vision of commitment produced in Fearon's and Protoje's lyrics has emphasised a certain degree of coherence and a number of commonalities. Nevertheless, marked differences between the two artists' approaches should not be ignored. In Fearon's work for instance, commitment is expressed in a rather universal, abstract way in complete keeping with the aesthetics and the politics of 1970s roots reggae music in which he was a major participant. Pronouns like "you" and "I" or "us" and "them" for example are rarely given an antecedent and are thus more open to interpretation on the part of the listener or reader. Protoje's vision of his commitment on the other hand is firmly grounded in a number of very concrete claims and themes, like the use and legalisation of marijuana ("This Is NOT A Marijuana Song," "Bubblin"), the situation of Kingston inner cities ("Kingston Be Wise"), the denunciation of bling and gun culture in reggae music ("Reggae Revival," "The Flame") or gender issues ("Shot By Love," "Black Cinderella," "Stylin"). All of these are discussed extensively. In that respect, it would seem that Fearon's work reflects his life in exile and a more philosophical, abstract view of commitment while Protoje emphasises a connection to the actual working-class communities of Jamaica which he claims to represent.

These formal differences in the way common themes are treated can also be observed in the fact that Fearon uses very few words and produces a poetry that is very synthetic and borrows extensively from the proverbial and allegorical style of classic roots reggae. Protoje's style can be compared to that of reggae DJs chatting into the microphone about their daily concerns: he uses many more words, which incidentally allows him to engage in more formal experiments than Fearon. Fearon's lyrics mostly contain an even number of lines and fit into the $4 \times 4$ musical pattern of reggae riddims; most of his lyrics are also based on traditional rhyme schemes and sound patterns. Protoje's style is closer to that of US rappers, the number of words in lines and the rhyming patterns vary greatly, and he also resorts massively to the practices of enjambment and rhythmic disruption in his performance of the songs. Some of the images and metaphors he uses are also much less conventional and predictable than Fearon's, mostly because he anchors his work in the reality of today's Jamaican communities rather than resorting to the traditional repertoire of Rasta imagery. ${ }^{20}$

In musical terms, Fearon's and Protoje's styles are also very different, though they both claim to be writing and playing roots reggae music. Fearon's music is entirely instrumental, he plays a number of instruments himself and is accompanied by the Boogie Brown Band that produces a sound that is very close to that of 1970s productions, which reflects his commitment to the roots of reggae music. Protoje on the other hand sings to riddims that are for the most part computerised; only a few if fundamental instruments like the bass are recorded acoustically. On the whole, his sound is much more modern, including many elements of hip hop and pop music and rehashing classic reg-

writing process, these texts retain some of their oral characteristics and this implies a measure of instability and variation in the performance process: written transcriptions are renditions of a material that is likely to change depending on the performance context.

20. For example, Protoje compares the colour of his marijuana to that of the Ribena black currant juice, which is very popular in Jamaica, to indicate its high quality in "Who Dem A Program." In the same song, he mentions the gabardine, which is one of the favourite outfits of young Kingston Rastas, as a metaphor for divine protection, or uses the image of The Paragon (one of the biggest shopping malls in the world located in Singapore) to denounce overconsumption of material goods. 
gae tunes into electronic versions that sometimes do not contain many reggae elements in their composition and arrangements. Fearon's musical commitment could therefore be considered as more conservative in musical terms, imitating and repeating already existing musical formats despite a large amount of innovation and creativity, while Protoje's project relies on the idea of keeping the spirit of the music alive, rather than its actual features.

All in all, it would seem then that despite their similarities, Fearon's vision of commitment is more conservative than Protoje's in terms of the themes and form of his lyrics, and in terms of the composition and arrangements of his musical material. Yet, Protoje's work is not devoid of any form of conservatism, as can be seen notably in his position on gender issues, a theme that Fearon avoids completely in the two records studied here. In songs like "Black Cinderella" or "Stylin," Protoje fiercely denounces the vanity and superficiality of some of his former lovers and of Jamaican working-class women more generally. He opposes to this type of behaviour a vision of love based on harmony and exclusivity which can be seen as yet another form of commitment in a context of rampant male infidelity. Love is also seen as a form of empowerment which elevates both partners spiritually and thus can be seen as one of the dimensions of Rastafarian livity. Yet these songs display a vision of gender relationships based on a strict hierarchy between men and women which complicates Protoje's commitment in other domain: as Carolyn Cooper has shown, when it comes to gender issues the lyrics of the conscious Rastaman are often found to be more conservative than that of slackness DJs who to some extent promote a more liberated form of sexuality for both men and women. ${ }^{21}$

But the most problematic aspect of the form of commitment built into the lyrics of Fearon and Protoje is probably its very ambiguous use in the promotional and marketing strategy of these artists on the international pop music market. In a context where a lot of reggae music produced is sex- and violence-oriented, especially in Jamaica, and where this tendency is fiercely criticised, it becomes easier to sell reggae artists that go back to the international roots reggae style of the 1970s, and who can thus benefit from the legitimacy this type of reggae has established on the pop music market. It is worth noting that artists like Protoje, and even more so like Fearon, appeal for a great part to US and European audiences and are somewhat less popular in Jamaica itself than hardcore slackness DJs like Vybz Kartel or Mavado.

The sincerity of these artists' commitment could then be questioned, since it can be seen as a way to increase the financial income generated by their work by selling records to audiences that can spend more money on cultural products than Jamaican working-class inner-city residents. Yet this interpretation is not completely satisfactory considering that both artists are respected and loved in their home country, and that selling records has become an unavoidable part of any musician's career, whether s/he is committed or not. As Gilroy suggests, such artists also deconstruct the album as a commodity by using various strategies in their music and lyrics, but also in the making

21. In a groundbreaking essay, Cooper discusses the discourses on gender and female sexuality in the lyrics of Bob Marley and Shabba Ranks and shows that despite their respective reputations the slackness DJ might indeed be more progressive than the Rasta icon (Sound Clash 73-97). 
of the record as a material object. ${ }^{22}$ It seems then that even in a world where popular music can never fully escape the laws of the market, reggae artists like Fearon and Protoje still provide inspiring examples of a committed way of making music, writing lyrics, and living a musician's life.

David BousQueT Université de Bourgogne

\section{Works Cited}

BARNeTt, Michael. “The Many Faces of Rasta: Doctrinal Diversity within the Rastafari Movement." Caribbean Quarterly 51.2 (2005): 67-78.

BARRETT, Leonard. The Rastafarians: Sounds of Cultural Dissonance. Boston: Beacon P, 1977.

Barrow, Steve, and Peter Dalton. The Reggae Rough Guide, Updated Third Edition. 1997. London: Penguin, 2004.

Bradley, Lloyd. Bass Culture: When Reggae Was King. London: Penguin, 2000.

BreINER, Laurence. “The English Bible in Jamaican Rastafari." Journal of Religious Thought 42.2 (1985): 30-43.

Campbell, Horace. Rasta and Resistance. St John's, Antigua: Hansib, 1985.

Chevannes, Barry. Rastafari: Roots and Ideology. Syracuse, NY: Syracuse UP, 1994.

Cooper, Carolyn. Noises in the Blood - Orality, Gender and the "Vulgar" Body of Jamaican Popular Culture. London \& Basingstoke: Macmillan Caribbean, 1993.

-. Sound Clash: Jamaican Dancehall Culture At Large. New York \& Basingstoke: Palgrave Macmillan, 2004.

Dawes, Kwame. "Dichotomies of reading 'street poetry' and 'book poetry.” Critical Quarterly 38.4 (1996): 3-20.

—. Natural Mysticism: Towards A New Reggae Aesthetic In Caribbean Writing. Leeds: Peepal Tree, 1999.

Fearon, Clinton. Mi Deh Yah. Boogie Brown Productions \& Makafresh/Makasound, 2010.

—. Goodness. Boogie Brown Productions \& Chapter Two/Wagram, 2014.

GAYE, Abdoulaye. "De l'espace dancehall comme refuge cathartique à la Jamaïque." Espaces et sociétés 1.144-145 (2011): 105-19. <www.cairn.info/revue-espaces-et-societes-2011-1-page-105.htm>. Consulted 7 December 2015.

GILroY, Paul. There Ain't No Black in the Union Jack. London: Hutchinson, 1987.

—. The Black Atlantic: Modernity and Double Consciousness. Cambridge, MA: Harvard UP, 1993.

GLISSANT, Edouard. Le discours antillais. Paris: Gallimard, 1997.

LEE, Hélène. The First Rasta: Leonard Howell and the Rise of Rastafarianism. Chicago: Lawrence Hill, 2003.

Manuel, Peter, and Wayne Marshall. "The Riddim Method: Aesthetics, Practice, and Ownership in Jamaican Dancehall.” Popular Music 25.3 (2006): 447-70.

Owens, Joseph. Dread: The Rastafarians of Jamaica. Kingston: Sangster's, 1976.

PolLard, Velma. Dread Talk: The Language of Rastafari. Kingston: Canoe P, 1994.

Prahlad, Anand. Reggae Wisdom: Proverbs in Jamaican Music. Jackson: Mississippi UP, 2001.

PRotoje. The 8-Year Affair. Don Corleon Records, 2013.

-. Ancient Future. Overstand Entertainment, In.Digg.Nation Collective \& Baco Records, 2015.

Stephens, Michelle. "Marley, LLC Copyrighting the Legend." Review: Literature and Arts of the Americas 43.2 (2010): 218-25.

Stolzoff, Norman. Wake the Town and Tell the People: Dancehall Culture in Jamaica. Durham, NC: Duke UP, 2000.

ZIPS, Werner. Rastafari: A Universal Philosophy in the Third Millennium. Kingston: Ian Randle, 2006.

22. "[T] he basic units of commercial consumption in which music is fast frozen and sold have been systematically subverted by the practice of a racial politics that has colonised them [...]. From this perspective, the magical process whereby a commodity like a twelve-inch single, released from the belly of the multinational beast, comes to anticipate, even demand, supplementary creative input in the hidden spheres of public political interaction that wait further up on the road seems less mysterious" (Gilroy, The Black. Atlantic 105). It should also be noted here that Fearon and Protoje have both opted for the creation of their own record label (respectively Boogie Brown Productions and In.Digg.Nation Collective), thereby securing a high degree of artistic control on and financial autonomy in their work. 